\title{
Structure and Side-Chain Relaxations of D,L-Alternating Polypeptides
}

\author{
Masamitsu NAGAO, Takeshi SUZUKI, Shintaro SASAKI,* \\ and Ichitaro UEMATSU \\ Department of Polymer Chemistry, Tokyo Institute of Technology, \\ Ookayama, Meguro-ku, Tokyo, 152 Japan
}

(Received December 19, 1984)

\begin{abstract}
X-Ray and dielectric measurements were carried out for films of D,L-alternating poly $(\gamma$-benzyl glutamate) (PBDLG) and poly( $\gamma$-phenethyl glutamate) (PPDLG). PBDLG exists in the $\alpha$ - and $\omega$-helical conformations in films prepared by evaporating the solvent chloroform quickly and slowly, respectively. Both forms of PBDLG undergo an irreversible transition at $130-140^{\circ} \mathrm{C}$ to the $\pi_{\mathrm{DL}}$-helical structure specific to D,L-alternating polypeptides. PPDLG adopts the $\alpha$-helical conformation, and it is transformed to the $\pi_{\mathrm{DL}}$ conformation at $80-90^{\circ} \mathrm{C}$. PPDLG exhibits the large dielectric dispersion due to side-chain motion. The dispersion of the $\omega$ form of PBDLG is very small in comparison with those of the $\alpha$ and $\pi_{\mathrm{DL}}$ forms. The heat of transition and dielectric properties are discussed in terms of stacking of phenyl groups.

KEY WORDS D,L-Alternating Polypeptides / Poly $(\gamma$-benzyl glutamate) /

Poly $\left(\gamma\right.$-phenethyl glutamate) $/ \alpha$ Helix $/ \omega$ Helix $/ \pi_{\mathrm{DL}}$ Helix / Side-Chain

Dispersion / Stacking /
\end{abstract}

Structures specific to polypeptides with regular alternation of $D$ and $L$ residues have been explored in relation to the function of gramicidin A, a natural D,L-alternating ion carrier. Spach and co-workers investigated structures of $\mathrm{D}, \mathrm{L}$-alternating $\operatorname{poly}(\gamma$-benzyl glutamate) $\left[\left(-\mathrm{NHCHRC} \mathrm{O}^{\prime}\right)_{n}, \mathrm{R}=-\mathrm{CH}_{2} \mathrm{CH}_{2}-\right.$ $\mathrm{COOCH}_{2} \mathrm{C}_{6} \mathrm{H}_{5}$ ] (PBDLG) as a model polypeptide. $^{1-8}$ The $\mathrm{L}$ homopolymer (PBLG) and the random $\mathrm{D}, \mathrm{L}$-copolymer exist only in the $\alpha$-helical conformation as well as the randomcoil conformation. ${ }^{9,10}$ On the basis of conformational energy calculations, Ramachandran and Chandrasekaran ${ }^{11}$ suggested the possibility of the existence of some helical conformations specific to D,L-alternating polypeptides. Among these, the $\mathrm{LD}_{3}$ helix (the $\pi_{\mathrm{DL}}$ helix denoted by Spach et al.) has a structure similar to parallel $\beta$-pleated sheets rolled into helices (hence the nomenclature $\beta$ helix $\left.{ }^{12}\right)$. Hesselink and Scheraga ${ }^{13}$ indicated that the $\alpha$ helices of some D,L-alternating polypeptides have energies comparable to those of the right-handed $\alpha$ helices of the corresponding L homopolymers. The $\alpha$ helix denoted as $3.6_{13}$ helix ${ }^{14,15}$ contains 3.6 residues per turn with 13 atoms in a ring formed by a hydrogen bond (Figure 1a). The $\pi_{\mathrm{DL}}$ helix contains 2.2 dipeptide units per turn, and has alternating patterns of hydrogen bonds with 14 and 16 atoms in the rings (Figure 1b). The $\pi_{\mathrm{DL}}$ conformation is similar to that of the ordinary $\pi\left(4.4_{16}\right)$ helix which has been proposed for L polypeptides. ${ }^{16-18}$

Caille et $a l^{2}{ }^{2}$ synthesized $\mathrm{D}, \mathrm{L}$-alternating PBDLG by the racemization-free method proposed by Trudelle, ${ }^{19}$ and fractionated this polymer into two portions, (A) the high molec-

* To whom correspondence should be addressed. 


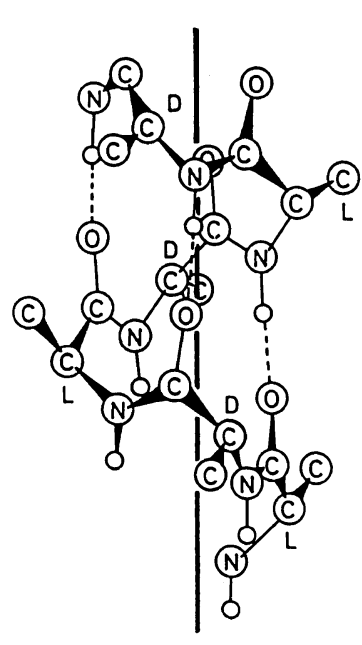

(a)

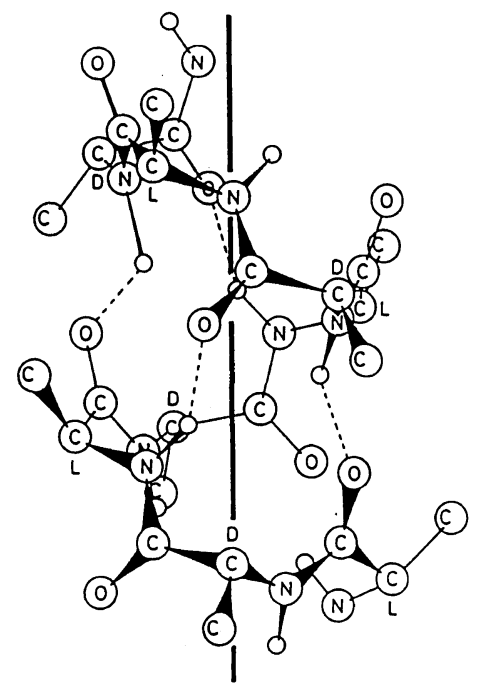

(b)

Figure 1. Molecular models for D,L-alternating polypeptides. (a) The $\alpha$ helix; (b) the $\pi_{\mathrm{DL}}$ helix.

ular weight component and (B) the low molecular weight one. PBDLG-(A) was shown to exist in the $\alpha$-helical conformation in films prepared from the solution in chloroform. ${ }^{3-5}$ This was transformed to the $\pi_{\mathrm{DL}}$ conformation at $130-150^{\circ} \mathrm{C}$, and then to the doublestranded $\pi \pi_{\mathrm{DL}}^{5.6}$ helix (5.6 residues per turn) at $220-230^{\circ} \mathrm{C}$. Dissolution and recasting of $\pi \pi_{\mathrm{DL}}^{5.6}$ gave other kinds of double-stranded helices..$^{5-7}$ The possibility of the existence of the $\omega\left(4.0_{13}\right)$ helix was suggested for the (A)component film cast from dimethylformamide (DMF) (or dioxane) containing a small amount of water. $^{3}$ For the (B)-component film, Spach et al. ${ }^{1,3,8}$ assumed the antiparallelchain polar pleated-sheet structure (polar $\beta$ conformation) proposed by De Santis et al. ${ }^{20}$

As already reported in a previous paper, ${ }^{21}$ we prepared $\mathrm{D}, \mathrm{L}$-alternating $\operatorname{poly}(\gamma$-phenethyl glutamate) (PPDLG) ( $\mathrm{R}=-\mathrm{CH}_{2} \mathrm{CH}_{2} \mathrm{COO}$ $\mathrm{CH}_{2} \mathrm{CH}_{2} \mathrm{C}_{6} \mathrm{H}_{5}$ ) and PBDLG, and fractionated them into two components (A) and (B). In this work, we report conformational changes in the (A)-component films of PBDLG and PPDLG caused by annealing. Dielectric properties associated with side-chain motion are discussed in terms of stacking of phenyl groups.

\section{EXPERIMENTAL}

PBDLG and PPDLG were prepared by the racemization-free method. ${ }^{19}$ The polycondensation of the LDLD-tetrapeptide 2-hydroxyphenyl esters (with the $N$-terminal L residue) was carried out in benzene at room temperature. The crude samples were fractionated into two portions, the high molecular weight component (A) and the low molecular weight one (B), respectively, as was described in a previous paper. ${ }^{21}$ The intrinsic viscosities of PBDLG-(A) and PPDLG-(A) in dichloroacetic acid at $25^{\circ} \mathrm{C}$ were about $20 \mathrm{~cm}^{3} \mathrm{~g}^{-1}$, which corresponds to a molecular weight $c a$. 25000 as evaluated from the relation due to Doty et $a .^{22} \mathrm{NMR}$ spectra of the polymer samples were exactly the same as those of the corresponding L homopolymers. However, the optical properties of the formers measured with a Jasco J-20 spectrophotometer were different from those of the latters. The MoffittYang $b_{0}$ parameters determined for $1 \%$ solutions in chloroform were $c a .300$ for PBDLG and ca. 160 for PPDLG, i.e., the both were 
positive in contrast to those for the L homopolymers. This supports the conclusion by Heitz and Spach $^{6}$ that the helix of finite length with the $N$-terminal L residue is preferentially left handed.

Solid films were obtained by drying solutions in chloroform over glass plates at room temperature. Oriented specimens were prepared by stroking concentrated solutions onto glass plates with a spatula in one direction. Annealing treatments were carried out under nitrogen atmosphere at several temperatures for $1 \mathrm{~h}$. Densities were measured by the flotation method in aqueous $\mathrm{KBr}$ solution at $25^{\circ} \mathrm{C}$.

$\mathrm{X}$-Ray diffraction photographs were taken with flat-plate and cylindrical cameras (Nifiltered $\mathrm{Cu} K_{\alpha}$ radiation was used). Reflection spacings were calibrated against reflections of silicon powder sprinkled over the specimen.

Infrared (IR) spectra were recorded by a Jasco DS-701G grating spectrophotometer. Dielectric measurements were performed with a transformer bridge type TR-10C Ando Electric Co. over a frequency range from $30 \mathrm{~Hz}$ to $1 \mathrm{MHz}$. Differential scanning calorimetric (DSC) measurements were made with a Perkin Elmer DSC model II instrument.

\section{RESULTS AND DISCUSSION}

\section{$\alpha$ Helix of $P B D L G$}

The IR spectrum of PBDLG-(A) film prepared by drying the solution in chloroform rather quickly (without any cover in a de-

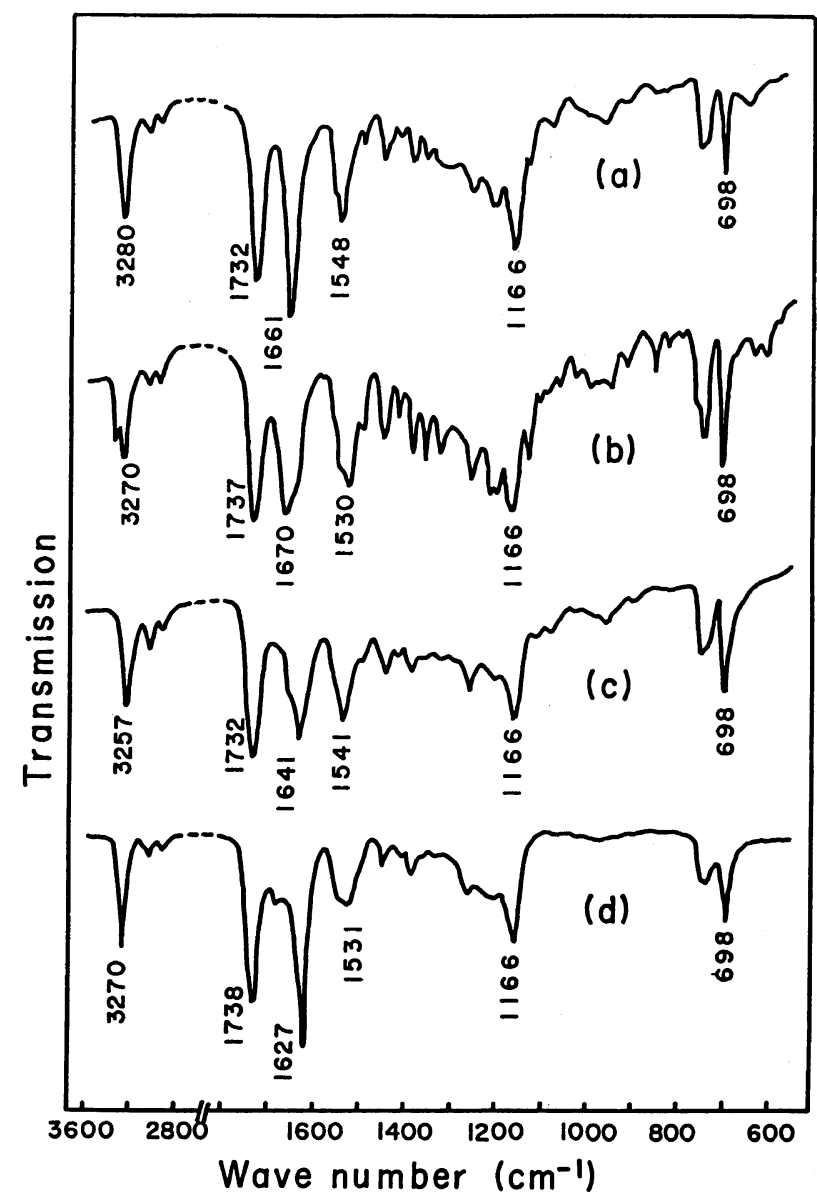

Figure 2. Infrared spectra of PBDLG-(A) in the (a) $\alpha$, (b) $\omega$, and (c) $\pi_{\mathrm{DL}}$ forms, and (d) of PBDLG-(B). 
Table I. Infrared frequencies for PBDLG and PPDLG films

\begin{tabular}{|c|c|c|c|c|}
\hline \multirow{2}{*}{ Polymer } & \multirow{2}{*}{$\begin{array}{c}\text { Molecular } \\
\text { conformation }\end{array}$} & \multicolumn{3}{|c|}{ Band positions $/ \mathrm{cm}^{-1}$} \\
\hline & & Amide A & Amide I & Amide II \\
\hline \multirow[t]{3}{*}{ PBDLG } & $\alpha$ & 3280 & 1661 & 1548 \\
\hline & $\omega$ & $\begin{array}{l}3335 \\
3270\end{array}$ & 1670 & 1530 \\
\hline & $\begin{array}{c}\pi_{\mathrm{DL}} \\
\text { Polar } \beta,(\mathrm{B})\end{array}$ & $\begin{array}{l}3257 \\
3270\end{array}$ & $\begin{array}{l}1641 \\
1690(\mathrm{sh}) \\
1627\end{array}$ & $\begin{array}{l}1541 \\
1531\end{array}$ \\
\hline \multirow[t]{4}{*}{ PPDLG } & $\alpha$ & 3280 & 1661 & 1547 \\
\hline & $\pi_{\mathrm{DL}}$ & 3258 & 1640 & 1539 \\
\hline & Polar $\beta,(\mathrm{B})$ & 3272 & $1690(\mathrm{sh})$ & 1530 \\
\hline & & & 1626 & \\
\hline
\end{tabular}

a Shoulder bands are indicated by (sh).

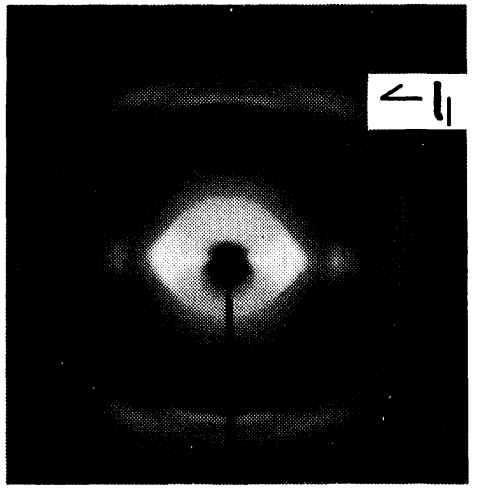

(a)

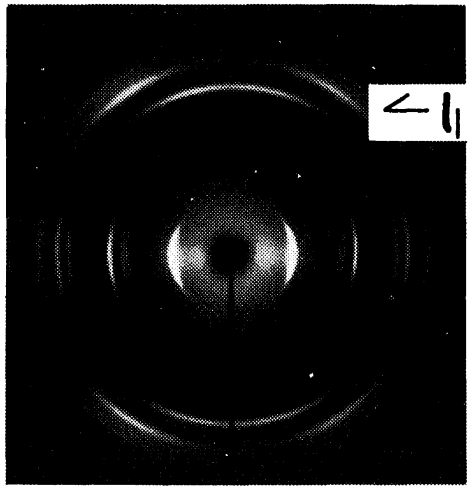

(b)

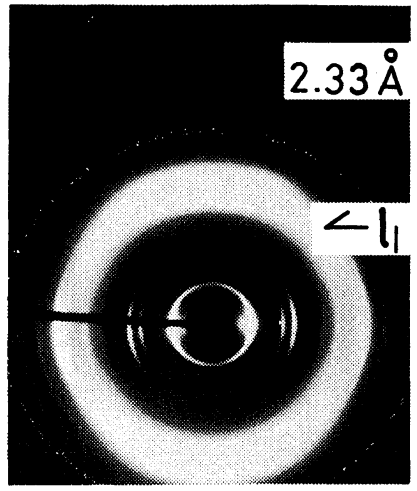

(c)

Figure 3. X-Ray diffraction patterns of PBDLG in the (a) $\alpha$, (b) $\omega$, and (c) $\pi_{\mathrm{DL}}$ forms. The orientation direction is vertical. The turn layer line is indicated by $l_{1}$.

siccator) exhibits absorptions characteristic of the $\alpha$-helical conformation at similar positions as for PBLG (Figure 2). Frequencies of the amide A, I, and II bands are listed in Table I. They are consistent with the data reported previously. ${ }^{3}$

The oriented $\alpha$ form exhibits a poor diffraction pattern (Figure 3a). Three broad equatorial reflections were explained by a hexagonal unit cell with dimension $15.0 \AA\left(\equiv a^{\prime}\right)$ containing a single chain, although Heitz et $a l .^{3}$ reported $a^{\prime}=15.3 \pm 0.1 \AA$. A meridional reflection corresponding to unit height $p$ appeared at $1.4_{7} \AA$ (the axial height per dipeptide unit $p_{\mathrm{DL}}$ is $2.9_{5} \AA$ ).

The strong layer line indicated by $l_{1}$ in Figure 3 is associated with the helix pitch $P$, and is termed the turn layer line, since the reciprocal coordinate $\zeta$ is given by $\zeta=P^{-1}$. In the diffraction pattern shown in Figure 3a, the turn layer line $\left(l_{1}\right)$ appears at $\zeta^{-1}=P=$ $5.4 \AA$. Therefore, the molecular conformation $(P / p \simeq 11 / 3)$ is close to the standard $\alpha$ helix $(P=5.40 \AA, p=1.50 \AA, P / p=18 / 5)$, as it has 11 
dipeptide units per six turns. However, Heitz et $a l^{3}$ reported that the turn layer line appeared as a streak at $\zeta^{-1}=5.60 \AA$. From the values of $P=5.60 \AA$ and $p=1.47 \AA$, they concluded that the molecular conformation was distorted from the standard $\alpha$ helix, as it had 19 residues per five turns $(P / p \simeq 19 / 5)$.

On the turn layer line, a rather sharp reflection $\left(5.2{ }_{5} \AA\right)$ and a broad one $(4.6 \AA)$ appear (Figure $3 a)$. The spacings are not explained by the single-chain hexagonal unit cell with dimension $a^{\prime}=15.0 \AA$ and $P=5.4 \AA$. The true unit cell has three times the cross section of the single-chain unit cell. Therefore, it is hexagonal with dimension $a=\sqrt{3} a^{\prime}=26.0 \AA$, and contains three helices (Tables II and III). This three-chain (crystallographically not hexagonal) unit cell has been found for $\operatorname{poly}(\gamma$ alkyl L-glutamate)s. ${ }^{23}$ The calculated density is consistent with the observed value (Table II).

\section{$\omega$ Helix of $P B D L G$}

By means of IR spectroscopy and electron microscopy, Heitz et al. ${ }^{3}$ suggested the existence of the $\omega$-helical conformation in the film cast from DMF (or dioxane)+water. They obtained only unoriented films. We prepared the oriented $\omega$ form by exposing the $\alpha$ form to the vapor of DMF + water. Specimens for IR measurements were prepared in the same way, and identified to be in the $\omega$ form as reported in Figure 2 and Table I.

The $\omega$ form exhibits a diffraction pattern with sharp Bragg reflections (Figure 3b). A meridional reflection corresponding to $p$ appeared on the fourth layer line at $1.35 \AA$. All reflections are indexed by an orthorhombic unit cell containing two helices with dimensions $a=27.1 \AA, b=15.5 \AA$, and $c=P=5.40 \AA$ (Tables II and III). The calculated density, $1.28 \mathrm{~g} \mathrm{~cm}^{-3}$, is higher than those of the other forms (Table II).

A highly crystalline $\omega$ form $\left(\omega_{1}\right)$ was prepared also from the solution in chloroform by evaporating the solvent very slowly over a week. The crystallinity of this sample was
Table II. Structural parameters of PBDLG and PPDLG

\begin{tabular}{|c|c|c|c|c|}
\hline \multirow{2}{*}{ Polymer } & \multirow{2}{*}{$\begin{array}{c}\text { Helix } \\
\text { type }\end{array}$} & \multirow{2}{*}{ Lattice parameters } & \multicolumn{2}{|c|}{ Density $/ \mathrm{g} \mathrm{cm}^{-3}$} \\
\hline & & & Calcd & Obsd \\
\hline \multirow[t]{3}{*}{ PBDLG } & $\alpha$ & $\begin{array}{l}\text { Hexagonal, } a=26.0 \AA \\
\left(a^{\prime}=15.0 \AA\right), P= \\
5.4 \AA, p=1.4_{7} \AA\end{array}$ & 1.27 & 1.25 \\
\hline & $\omega$ & $\begin{array}{l}\text { Orthorhombic, } a= \\
27.1 \AA, b=15.5 \AA \\
c=P=5.40 \AA \\
p=1.35 \AA\end{array}$ & 1.28 & 1.26 \\
\hline & $\pi_{\mathrm{DL}}$ & $\begin{array}{l}\text { Hexagonal, } a=17.0_{2} \AA \\
c=25.6 \AA, P= \\
5.1_{2} \AA, p_{\mathrm{DL}}=2.3_{3} \AA\end{array}$ & 1.25 & 1.25 \\
\hline \multirow[t]{2}{*}{ PPDLG } & $\alpha$ & $\begin{array}{l}\text { Hexagonal, } a=27.5 \AA \\
\left(a^{\prime}=15.9 \AA\right), P= \\
5.4 \AA, p=1.4_{7} \AA\end{array}$ & 1.21 & 1.20 \\
\hline & $\pi_{\mathrm{DL}}$ & $\begin{array}{l}\text { Hexagonal, } a=17.6 \AA \\
c=25.7 \AA, P= \\
5.1_{4} \AA, p_{\mathrm{DL}}=2.3_{4} \AA\end{array}$ & 1.23 & 1.23 \\
\hline
\end{tabular}

higher than that of the $\omega$ form $\left(\omega_{2}\right)$ prepared by treating the $\alpha$ form with the vapor of $\mathrm{DMF}+$ water. Dielectric properties of the $\omega_{1}$ and $\omega_{2}$ films are compared below.

\section{$\pi_{\mathrm{DL}}$ Helix of $P B D L G$}

A structural transition was observed for the $\alpha$ and $\omega$ forms at about $130^{\circ} \mathrm{C}$ by DSC measurements. The IR (Figure 2 and Table I) and X-ray data (Tables II and III) for the film annealed at $165^{\circ} \mathrm{C}$ were identical with those assigned to the $\pi_{\mathrm{DL}}$ form by Heitz et al. $^{3}$

The meridional reflections corresponding to $p$ and $p_{\mathrm{DL}}$ are observed at $1.1_{7}$ and $2.3_{3} \AA$, respectively (Figure $3 \mathrm{c}$ ). The layer-line intensity distribution was in good agreement with the calculations by Lotz et al. ${ }^{5}$ for the $\pi_{\mathrm{DL}^{-}}$ helical model with 11 dipeptide units per five turns. The equatorial reflections are explained by a hexagonal unit cell with dimension $a=$ $17.0_{2} \AA$ (Tables II and III). The calculated density agrees with the observed value $1.25 \mathrm{~g}$ $\mathrm{cm}^{-3}$. 
M. NAGAO et al.

Table III. X-Ray data of PBDLG

Table III. (continued)

\begin{tabular}{|c|c|c|c|c|c|c|c|c|c|c|c|c|c|}
\hline \multirow{2}{*}{$\frac{\text { Form }}{\alpha \text { Helix }}$} & \multicolumn{3}{|c|}{$h k l^{\mathrm{a}}$} & \multirow{2}{*}{$\frac{d_{\text {calcd }} / \AA^{\mathrm{b}}}{13.0}$} & \multirow{2}{*}{$\frac{d_{\text {obsd }} / \AA}{13.0}$} & \multirow{2}{*}{$\frac{\text { Intensity }^{\mathrm{c}}}{\text { vs }}$} & \multirow[t]{2}{*}{ Form } & \multicolumn{3}{|c|}{$h k l^{\mathrm{a}}$} & \multirow{3}{*}{$\begin{array}{c}d_{\text {calcd }} / \AA^{\mathrm{b}} \\
4.07 \\
3.71\end{array}$} & \multirow{2}{*}{$\frac{d_{\mathrm{obsd}} / \AA}{4.07}$} & \multirow{2}{*}{$\frac{\text { Intensity }^{\mathrm{c}}}{\mathrm{s}}$} \\
\hline & 1 & 1 & 0 & & & & & 4 & 1 & 1 & & & \\
\hline & 3 & 0 & 0 & 7.5 & 7.5 & $\mathrm{~m}$ & & 5 & 1 & 1 & & & \\
\hline & 2 & 2 & 0 & 6.5 & 6.5 & vw & & 4 & 2 & 1 & 3.71 & 3.71 & $\mathrm{~s}$ \\
\hline & 1 & 0 & $l_{1}$ & 5.25 & 5.25 & $\mathrm{~m}$ & & 1 & 3 & 1 & 3.70 & & \\
\hline & 2 & 0 & $l_{1}$ & $4.87\}$ & & & & 2 & 3 & 1 & 3.60 & 3.60 & vw \\
\hline & 2 & 1 & $l_{1}$ & $4.56\}$ & ca. 4.6 & w & & 5 & 2 & 1 & $3.43\}$ & & \\
\hline & 0 & 0 & $l_{2}$ & 1.47 & 1.47 & $\mathrm{w}$ & & 6 & 1 & 1 & $3.38\}$ & 3.4 & $\mathrm{~m}$ \\
\hline & & & $i_{2}$ & & 1.41 & w & & 7 & 0 & 1 & $3.15\}$ & & \\
\hline$\omega$ Helix & 1 & 1 & 0 & $13.46\}$ & & & & 7 & 1 & 1 & $3.08\}$ & 5.1 & W \\
\hline & 2 & 0 & 0 & $13.55\}$ & 13.5 & vs & & 7 & 2 & 1 & 2.927 & & \\
\hline & 2 & 1 & 0 & 10.20 & 10.2 & vw & & 6 & 3 & 1 & $2.88\}$ & 2.9 & $\mathrm{w}$ \\
\hline & 3 & 1 & 0 & $7.80\}$ & & & & 8 & 0 & 1 & $2.87 J$ & & \\
\hline & 0 & 2 & 0 & $7.75\}$ & 7.77 & $\mathrm{w}$ & & 8 & 2 & 1 & 2.69 & & \\
\hline & 1 & 2 & 0 & 7.45 & 7.44 & & & 7 & 3 & 1 & 2.69 & & \\
\hline & 4 & 0 & 0 & 6.77 & & W & & 0 & 5 & 1 & 2.69 & 2.69 & $\mathrm{~m}$ \\
\hline & 2 & 2 & 0 & 6.73 & 6.73 & $\mathrm{~s}$ & & 1 & 5 & 1 & 2.68 & & \\
\hline & 4 & 1 & 0 & 6.21 & & & & 10 & 2 & 1 & $2.31]$ & & \\
\hline & 3 & 2 & 0 & 5.88 & $\begin{array}{l}6.22 \\
5.88\end{array}$ & vw & & 8 & 4 & 1 & 2.31 & & \\
\hline & 5 & 1 & 0 & $5.12\}$ & 5.88 & $\mathrm{vw}$ & & 6 & 5 & 1 & 2.31 & 2.30 & $\mathrm{vw}$ \\
\hline & 4 & 2 & 0 & $5.10\}$ & 5.11 & $\mathrm{~s}$ & & 2 & 6 & 1 & 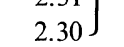 & & \\
\hline & 2 & 3 & 0 & 4.83 & & & & 7 & 5 & 1 & 2.21 ) & & \\
\hline & 3 & 3 & 0 & $\begin{array}{l}4.05 \\
4.48\end{array}$ & 4.82 & $\mathrm{~s}$ & & 4 & 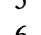 & & $\left.\begin{array}{l}2.21 \\
2.20\end{array}\right\}$ & & \\
\hline & 5 & 2 & 0 & $\left.\begin{array}{l}4.40 \\
4.44\end{array}\right\}$ & 4.45 & W & & 4 & 6 & 1 & $\left.\begin{array}{l}2.20 \\
2.19\end{array}\right\}$ & 2.19 & vw \\
\hline & 6 & 1 & 0 & 4.34 & & & & 10 & 3 & 1 & $\begin{array}{l}2.19) \\
2.51\end{array}$ & & \\
\hline & 4 & 3 & 0 & 4.11 & $\begin{array}{l}4.33 \\
4.10\end{array}$ & $\mathrm{~m}$ & & 2 & 2 & 2 & $2.51\}$ & 2.52 & $\mathrm{~m}$ \\
\hline & 6 & 2 & 0 & $3.90\}$ & 4.10 & $\mathrm{~m}$ & & 4 & 0 & 2 & $2.51\}$ & $2 . J 2$ & $\mathrm{~m}$ \\
\hline & 0 & 4 & 0 & & 3.89 & & & 5 & 1 & 2 & 2.397 & & \\
\hline & 7 & 1 & 0 & $3.76)$ & & $\mathrm{s}$ & & 4 & 2 & 2 & 2.39 & 2.39 & \\
\hline & & 3 & 0 & & & & & 0 & 3 & 2 & 2.39 & 2.39 & $\mathrm{~s}$ \\
\hline & $\begin{array}{l}5 \\
2\end{array}$ & & 0 & $\left.\begin{array}{l}3.74 \\
3.73\end{array}\right\}$ & 3.73 & $\mathrm{~m}$ & & 1 & 3 & 2 & $2.38 \mathrm{~J}$ & & \\
\hline & & $\begin{array}{l}4 \\
3\end{array}$ & & $\begin{array}{l}3.73) \\
3.40)\end{array}$ & & & & 7 & 2 & 2 & $2.13]$ & & \\
\hline & 6 & 3 & 0 & & & & & 6 & 3 & 2 & 2.11 & & \\
\hline & 8 & 0 & 0 & $3.39\}$ & 3.39 & $\mathrm{~m}$ & & 4 & 4 & 2 & 2.11 & 2.11 & $\mathrm{w}$ \\
\hline & 4 & 4 & 0 & $3.36)$ & & & & 8 & 0 & 2 & $2.11 \mathrm{~J}$ & & \\
\hline & 8 & 2 & 0 & 3.107 & & & & 2 & 5 & 2 & 2.017 & & \\
\hline & 7 & 3 & 0 & $3.10\}$ & 3.11 & w & & 9 & 0 & 2 & 2.01 & & \\
\hline & 1 & 5 & 0 & 3.08 & & & & 3 & 5 & 2 & 1.99 & 2.0 & w \\
\hline & 9 & 1 & 0 & 2.967 & & & & 6 & 4 & 2 & 1.99 & & \\
\hline & 6 & 4 & 0 & $2.94\}$ & 2.94 & W & & 9 & 1 & 2 & 1.99 & & \\
\hline & 3 & 5 & 0 & 2.93 & דינ. & & & 0 & 1 & 3 & 1.79 & & \\
\hline & 10 & 2 & 0 & 2.567 & & & & 1 & 1 & 3 & $1.78\}$ & & \\
\hline & 8 & 4 & 0 & 2.55 & & & & & 0 & 3 & $1.78\}$ & 1.79 & $\mathrm{~m}$ \\
\hline & 6 & 5 & 0 & 2.55 & 2.54 & vw & & 2 & 3 & 3 & 1.70 & & \\
\hline & 2 & 6 & 0 & 2.54 & & & & 0 & 3 & $\begin{array}{l}3 \\
3\end{array}$ & $\begin{array}{l}1.10 \\
1.70\end{array}$ & & \\
\hline & 4 & 6 & 0 & $\begin{array}{l}2.54 J \\
2.41)\end{array}$ & & & & 1 & 3 & 3 & $\begin{array}{l}1.70 \\
1.70\end{array}$ & & \\
\hline & 10 & 3 & 0 & $\left.\begin{array}{l}2.41 \\
2.40\end{array}\right\}$ & 2.39 & & & 4 & 2 & 3 & 1.70 & 1.69 & $\mathrm{~m}$ \\
\hline & 9 & 4 & 0 & 2.38 & & VW & & 5 & 1 & 3 & 1.70 & & \\
\hline & 1 & 1 & 1 & $5.01\}$ & & & & 2 & 3 & 3 & 1.69 & & \\
\hline & 2 & 0 & 1 & $5.02\}$ & 5.01 & vs & & 0 & 0 & 4 & 1.35 & 1.35 & $\mathrm{~m}$ \\
\hline & 2 & 1 & 1 & 4.77 & 4.76 & & & & & & & & \\
\hline & 3 & 1 & 1 & $4.44\}$ & & vw & $\pi_{\mathrm{DL}}$ Helix & 1 & 0 & 0 & 14.74 & 14.8 & vs \\
\hline & 0 & 2 & 1 & $4.43\}$ & 4.42 & w & & 1 & 1 & 0 & 8.51 & 8.51 & $\mathrm{~m}$ \\
\hline & 4 & 0 & 1 & 4.22 ? & & & & 2 & 0 & 0 & 7.37 & 7.37 & $\mathrm{~m}$ \\
\hline & 2 & 2 & 1 & $4.21\}$ & 4.22 & $\mathrm{w}$ & & 2 & 1 & 0 & 5.57 & 5.56 & $\mathrm{vw}$ \\
\hline & & & & 4.21 & & & & 3 & 0 & 0 & 4.91 & 4.92 & $\mathrm{w}$ \\
\hline
\end{tabular}


Table III. (continued)

\begin{tabular}{ccccccc}
\hline Form & $h k l^{\mathrm{a}}$ & $d_{\text {calcd }} / \AA^{\mathrm{b}}$ & $d_{\text {obsd }} / \AA$ & Intensity $^{\mathrm{c}}$ \\
\hline 2 & 2 & 0 & 4.26 & 4.26 & $\mathrm{~m}$ \\
3 & 1 & 0 & 4.09 & 4.09 & $\mathrm{~s}$ \\
4 & 0 & 0 & 3.69 & 3.68 & $\mathrm{~m}$ \\
3 & 2 & 0 & 3.38 & 3.39 & $\mathrm{~m}$ \\
4 & 1 & 0 & 3.22 & 3.22 & $\mathrm{vw}$ \\
$l=5$ & & - & $c a .4 .7$ & $\mathrm{~s}$ \\
$l=6$ & & - & $c a .4 .1$ & $\mathrm{~s}$ \\
0 & 0 & 11 & 2.33 & 2.33 & $\mathrm{~s}$ \\
$l=16$ & & - & $c a .1 .6$ & $\mathrm{vw}$ \\
$l=$ & 17 & & - & $c a .1 .5$ & $\mathrm{vw}$ \\
0 & 0 & 22 & 1.16 & 1.17 & $\mathrm{vw}$
\end{tabular}

a The indices $l_{1}$ and $l_{2}$ are associated with the layer lines with spacings $\zeta=P^{-1}$ and $p^{-1}$, respectively.

b Calculation is based on the parameters given in Table II.

c vs, very strong; s, strong; m, moderate; w, weak; vw, very weak.

$\alpha$ and $\pi_{\mathrm{DL}}$ Helices of PPDLG

The IR and X-ray data of PPDLG films resemble those of PBDLG, although the $\omega$ form has not been found for PPDLG. The transition from $\alpha$ to $\pi_{\mathrm{DL}}$ was observed at about $85^{\circ} \mathrm{C}$.

The oriented $\alpha$ form showed a broad diffraction pattern (Figure $4 \mathrm{a}$ ). The equatorial reflections were explained by a hexagonal unit cell with dimension $a^{\prime}=15.9 \AA$, except the $22.1 \AA$ reflection. This reflection was attributed to the polar $\beta$ structure. ${ }^{21}$ The spacing corresponds to the distance between neighboring pleated sheets. On the turn layer line at $\zeta^{-1}=$ $P=5.4 \AA$, two broad reflections (5.2 and $4.7 \AA$ ) appear. To explain these spacings, a threechain hexagonal unit cell with dimension $a=$ $27.5 \AA$ is assumed in a similar way as described for the $\alpha$ form of PBDLG (Tables II and IV). A meridional reflection corresponding to $p$ was observed at $1.4_{7} \AA$. The helical parameters are the same for the $\alpha$ helices of PBDLG and PPDLG.

The diffraction pattern of the $\pi_{\mathrm{DL}}$ form of PPDLG (Figure 4b) is very similar to that of PBDLG (Figure 3c). The meridional reflections corresponding to $p$ and $p_{\mathrm{DL}}$ appeared at
Table IV. X-Ray data of PPDLG ${ }^{a}$

\begin{tabular}{|c|c|c|c|c|c|c|}
\hline Form & \multicolumn{3}{|c|}{$h k l$} & $d_{\text {calcd }} / \AA$ & $d_{\text {obsd }} / \AA$ & Intensity \\
\hline \multirow[t]{10}{*}{$\alpha$ Helix } & \multicolumn{3}{|c|}{ (B) } & - & 22.1 & w \\
\hline & 1 & 1 & 0 & 13.75 & 13.8 & vs \\
\hline & 3 & 0 & 0 & 7.94 & 7.9 & $\mathrm{w}$ \\
\hline & 2 & 2 & 0 & 6.88 & 6.9 & w \\
\hline & 4 & 1 & 0 & 5.20 & 5.2 & vw \\
\hline & 1 & 0 & $l_{1}$ & $5.27\}$ & & \\
\hline & 1 & 1 & $l_{1}$ & $5.03\}$ & ca. 5.2 & W \\
\hline & 2 & 0 & $l_{1}$ & $4.92\}$ & & \\
\hline & 2 & 1 & $l_{1}$ & $4.63\}$ & ca. 4.7 & $\mathrm{~m}$ \\
\hline & 0 & 0 & $l_{2}$ & 1.47 & 1.47 & w \\
\hline \multirow[t]{11}{*}{$\pi_{\mathrm{DL}}$ Helix } & \multicolumn{3}{|c|}{ (B) } & - & 22.1 & $\mathrm{w}$ \\
\hline & 1 & 0 & 0 & 15.24 & 15.2 & vs \\
\hline & 1 & 1 & 0 & 8.80 & 8.78 & $\mathrm{w}$ \\
\hline & 2 & 0 & 0 & 7.62 & 7.61 & w \\
\hline & 2 & 2 & 0 & 4.40 & 4.40 & $\mathrm{vw}$ \\
\hline & 3 & 1 & 0 & 4.23 & 4.22 & vw \\
\hline & 4 & 0 & 0 & 3.81 & 3.80 & vw \\
\hline & \multicolumn{3}{|c|}{$l=5$} & - & ca. 4.7 & vs \\
\hline & \multicolumn{3}{|c|}{$l=6$} & - & ca. 4.0 & s \\
\hline & 0 & 0 & 11 & 2.34 & 2.34 & $\mathrm{~s}$ \\
\hline & 0 & 0 & 22 & 1.17 & 1.17 & $w$ \\
\hline
\end{tabular}

a Notation is the same as in Table III.

$1.1_{7}$ and $2.3_{4} \AA$, respectively. Equatorial reflections are indexed by a hexagonal unit cell with dimension $a=17.6 \AA$, except the reflection at $22.1 \AA$ assignable to the polar $\beta$ structure (Tables II and IV).

The $\pi_{\mathrm{DL}}$ form of PPDLG is denser than is the $\alpha$ form, while the $\pi_{\mathrm{DL}}$ form of PBDLG is less denser than are other forms (Table II).

\section{Dielectric Properties}

Frequency dependence of the dielectric constant $\left(\varepsilon^{\prime}\right)$ and the loss factor $\left(\varepsilon^{\prime \prime}\right)$ of PBDLG and PPDLG films are shown in Figures 5-10, where some data points are omitted for the sake of simplicity.

Figure 8 will facilitate a mutual comparison of the dielectric data at $30^{\circ} \mathrm{C}$ for four samples of PBDLG. The dispersions of $\omega_{1}$ and $\omega_{2}$ forms are broad and small in comparison with those of $\alpha$ and $\pi_{\mathrm{DL}}$ forms. The $\omega_{1}$ film is of higher crystallinity and of a smaller relaxation strength than is the $\omega_{2}$ film. 


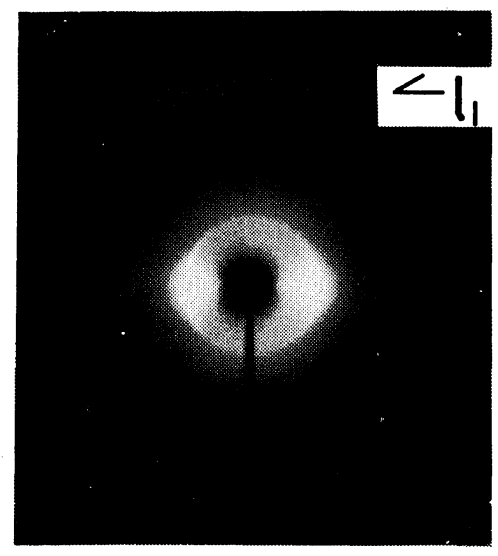

(a)

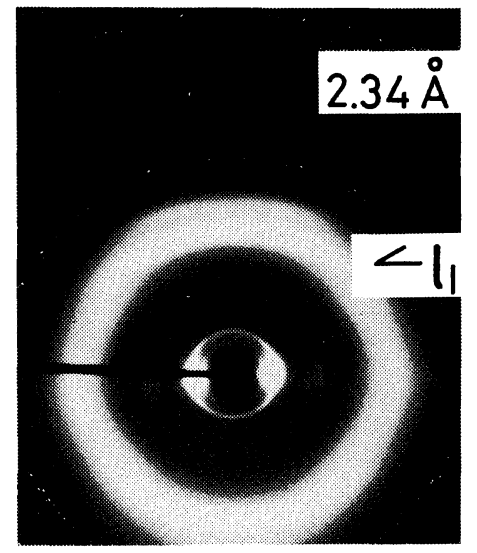

(b)

Figure 4. X-Ray diffraction patterns of PPDLG in the (a) $\alpha$ and (b) $\pi_{D L}$ forms. The orientation direction is vertical. The turn layer line is indicated by $l_{1}$.

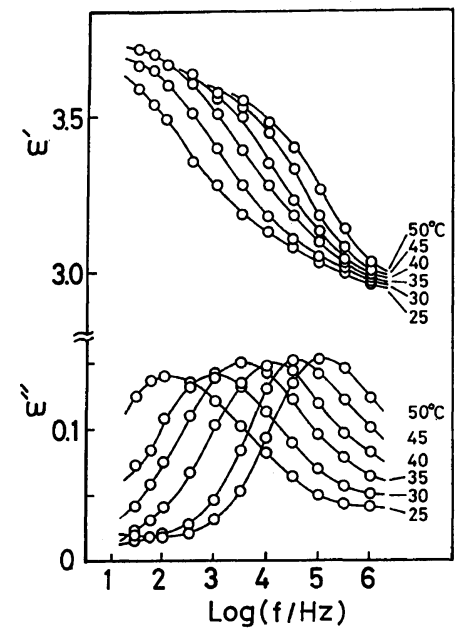

Figure 5. Frequency dependence of $\varepsilon^{\prime}$ and $\varepsilon^{\prime \prime}$ for the $\alpha$ form of PBDLG.

These dielectric properties indicate that the side-chain motion is restricted in the $\omega$ form, especially in the $\omega_{1}$ film, but not in the $\pi_{\mathrm{DL}}$ form. Somewhat orderly arrangements of side chains in the $\omega$ form are inferred from its high crystallinity and density (Table II).

The $\alpha$ and $\pi_{\mathrm{DL}}$ forms of PPDLG exhibit the large dielectric dispersions (Figures 9 and 10). Therefore, the side-chain interactions quoted

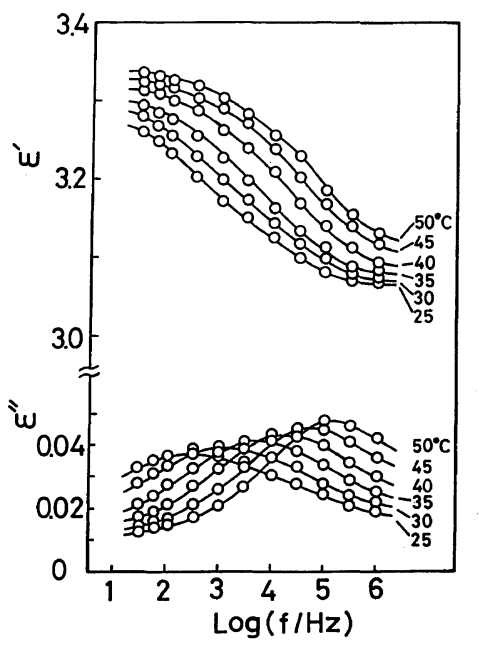

Figure 6. Frequency dependence of $\varepsilon^{\prime}$ and $\varepsilon^{\prime \prime}$ for the $\omega_{1}$ form of PBDLG.

for PBDLG do not exist for PPDLG.

Specific interactions of side chains have been investigated for PBLG, ${ }^{24,25}$ the racemic mixture (PBLG + PBDG), ${ }^{26-33}$ and some other polypeptides. $^{34}$ The racemic form of PBLG + PBDG $(1: 1)$ exhibits at about $95^{\circ} \mathrm{C}$ a reversible first-order transition associated with the collapse and reformation of stacking of phenyl groups. ${ }^{28}$ The side-chain dispersion 


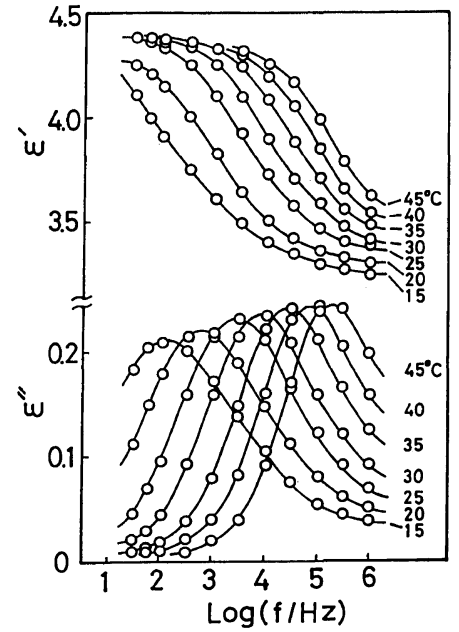

Figure 7. Frequency dependence of $\varepsilon^{\prime}$ and $\varepsilon^{\prime \prime}$ for the $\pi_{\mathrm{DL}}$ form of PBDLG.

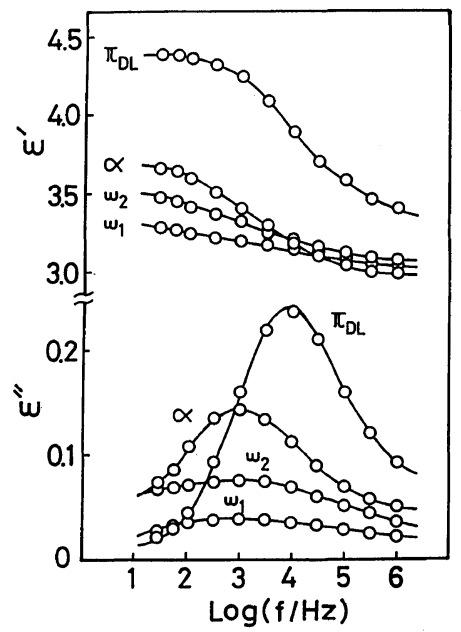

Figure 8. Frequency dependence of $\varepsilon^{\prime}$ and $\varepsilon^{\prime \prime}$ for PBDLG films at $30^{\circ} \mathrm{C}$.

was shown to be markedly reduced in the mixture. $^{29-31}$

The logarithms of frequencies at loss maxima are plotted against reciprocal temperature in Figures 11 and 12. The data of the corresponding homopolymers (PBLG and PPLG) and the racemic mixtures ${ }^{31,34}$ are included for comparison. The relationship between the relaxation time and temperature seems to be a WLF type, except for

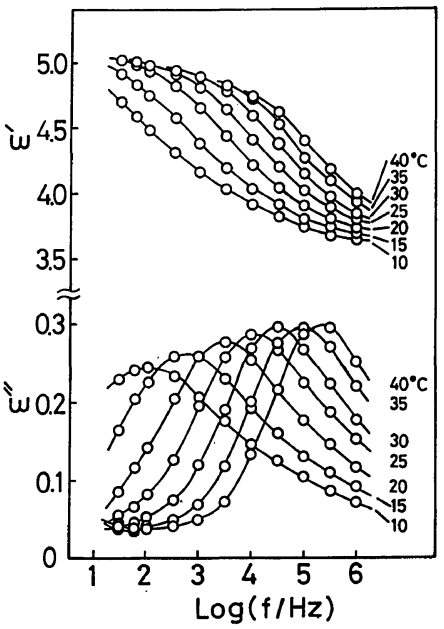

Figure 9. Frequency dependence of $\varepsilon^{\prime}$ and $\varepsilon^{\prime \prime}$ for the $\alpha$ form of PPDLG.

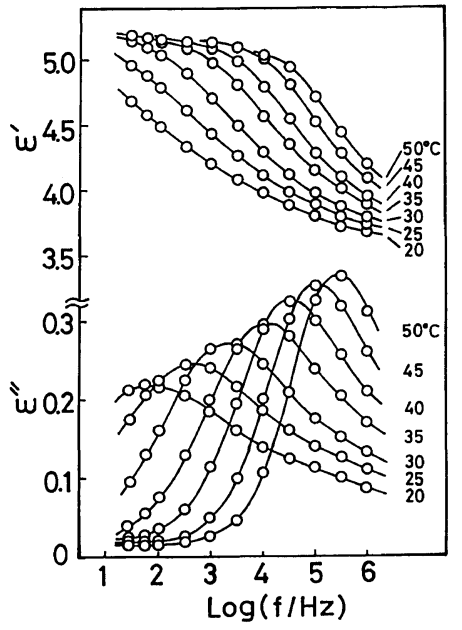

Figure 10. Frequency dependence of $\varepsilon^{\prime}$ and $\varepsilon^{\prime \prime}$ for the $\pi_{\mathrm{DL}}$ form of PPDLG.

PBLG + PBDG following the Arrhenius equation. Apparent activation energies estimated at $30^{\circ} \mathrm{C}$ are 50-60 kcal mol ${ }^{-1}$ for $\alpha$ and $\omega$ of PBDLG and $\pi_{\mathrm{DL}}$ of PPDLG, and ca. $40 \mathrm{kcal}$ $\mathrm{mol}^{-1}$ for $\pi_{\mathrm{DL}}$ of PBDLG and $\alpha$ of PPDLG.

The dispersion of the $\pi_{\mathrm{DL}}$ form of PBDLG is observed in the higher frequency (i.e., lower temperature) range in comparison with those of the $\alpha$ and $\omega$ forms (Figure 11). On the contrary, the dispersion of the $\pi_{\mathrm{DL}}$ form of 


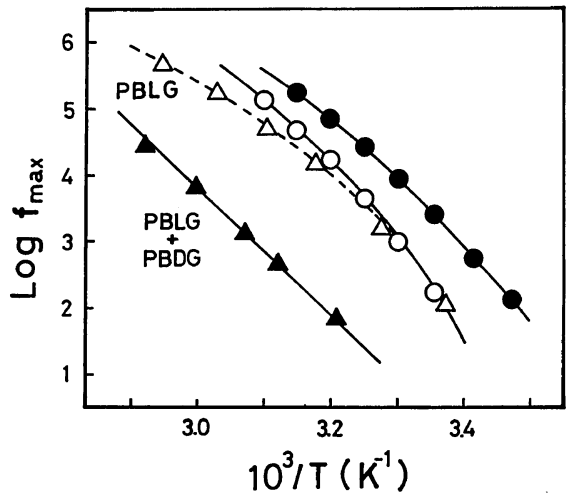

Figure 11. Plots of logarithm of the maximum-loss frequency $v s$. reciprocal temperature for $\operatorname{poly}(\gamma$-benzyl glutamate)s: $O$, the $\alpha$ and $\omega\left(\omega_{1}\right.$ and $\left.\omega_{2}\right)$ forms of PBDLG; 9 , the $\pi_{\mathrm{DL}}$ form of PBDLG; $\triangle$, PBLG (ref 31); $\boldsymbol{\Delta}$, PBLG + PBDG $(1: 1)($ ref 31$)$.

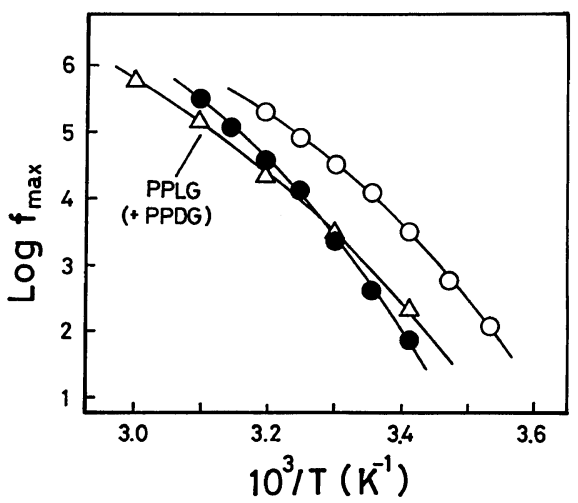

Figure 12. Plots of logarithm of the maximum-loss frequency $v s$. reciprocal temperature for $\operatorname{poly}(\gamma-$ phenethyl glutamate)s: $\bigcirc$, the $\alpha$ form of PPDLG; $\bigcirc$, the $\pi_{\mathrm{DL}}$ form of PPDLG; $\triangle$, PPLG and PPLG + PPDG $(1: 1)$ (ref 34).

PPDLG shifts to lower frequencies compared to the $\alpha$ form. This shift may reflect a certain kind of side-chain order in the $\pi_{\mathrm{DL}}$ form of PPDLG, and is consistent with the density data (Table II). The dispersion of the $\pi_{\mathrm{DL}}$ form of PPDLG appears in a slightly lower frequency range than does that of the $\pi_{\mathrm{DL}}$ form of PBDLG. This is rather unusual, since in the case of the same backbone conformation the dispersion generally shifts to higher frequencies as the side chain becomes longer. The

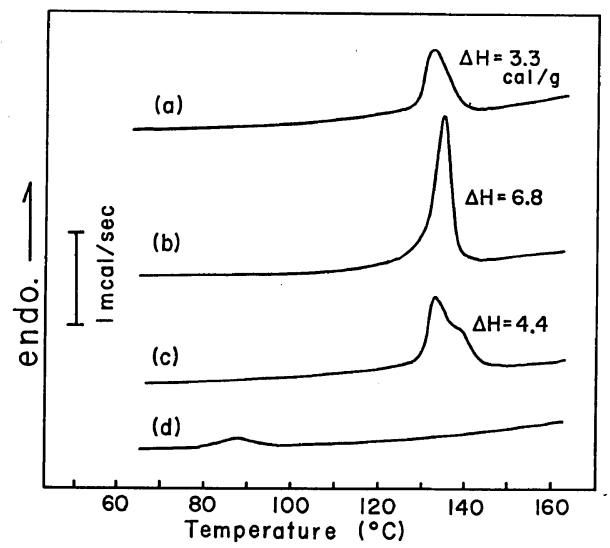

Figure 13. DSC curves for PBDLG in the (a) $\alpha$, (b) $\omega_{1}$, and (c) $\omega_{2}$ forms, and (d) for the $\alpha$ form of PPDLG. The heating rate is $10 \mathrm{deg} \mathrm{min}^{-1}$, and the sample weight is $10 \mathrm{mg}$.

sample of PPDLG contains the polar $\beta$ conformation as mentioned above, and this may shift the dispersion in excess to lower frequencies. The IR and X-ray data indicated that the amount of the polar $\beta$ conformation increased with annealing. Actually, the dispersion shifted to lower frequencies with the prolonged annealing treatments.

\section{Transition from $\alpha($ or $\omega)$ to $\pi_{\mathrm{DL}}$}

The transition to $\pi_{\mathrm{DL}}$ is detected in DSC curves at about $130^{\circ} \mathrm{C}$ for the $\alpha$ and $\omega$ forms of PBDLG, and at about $85^{\circ} \mathrm{C}$ for the $\alpha$ form of PPDLG (Figure 13). Since the $\alpha$ (or $\omega$ ) and $\pi_{\mathrm{DL}}$ helices have different patterns of hydrogen bonding, the transition involves the rupture and reorganization of all hydrogen bonds. The mechanism was discussed by Heitz et $a .^{3}$

The large heats of transition observed for PBDLG may be attributed to the collapse of stacking of phenyl groups. The reason is as follows. First, the transition temperature and the magnitude of the heats are such that expectable for the breakdown of stacks, as has been observed for PBLG and PBLG+ PBDG. ${ }^{24-33}$ Second, the magnitude of the heat of transition is inversely related to the 
relaxation strength of the dielectric dispersion qualitatively. The highly crystalline $\omega_{1}$ film exhibits the larger heat of transition and the smaller dispersion than the $\omega_{2}$ film. The $\alpha$ form of PBDLG exhibits the larger heat than PPDLG which is free from the stacking as inferred from the dielectric behavior. Therefore, phenyl groups in the $\omega$ form are considered to be stacked, and hence the stacked side chains do not contribute to the dispersion. The stacking is probably formed to some extent in the $\alpha$ form of PBDLG, as inferred from the dielectric and thermal properties. The shift to lower frequencies of the dispersions of the $\alpha$ and $\omega$ forms compared to the $\pi_{\mathrm{DL}}$ form may be due to the influence of the regular stacks upon unstacked side chains.

Side-chain interactions in the racemic mixture have been observed for poly[ $\gamma-(3-$ phenylpropyl) glutamate] ( $\mathrm{R}=-\mathrm{CH}_{2} \mathrm{CH}_{2}$ $\left.\mathrm{COOCH}_{2} \mathrm{CH}_{2} \mathrm{CH}_{2} \mathrm{C}_{6} \mathrm{H}_{5}\right)$, but not for poly $(\gamma-$ phenethyl glutamate) (PPG) ${ }^{34}$ The dielectric properties for the L polymer (PPLG) and the racemic mixture (PPLG+PPDG) of PPG were not distinguishable. ${ }^{34}$ The side-chain orientation about the helix axis may not be appropriate for the stacking in PPG. D, LAlternating PPDLG studied here is presumably in the same situation.

\section{CONCLUSIONS}

Our results obtained for PBDLG and PPDLG agree substantially with those by Spach and co-workers, ${ }^{1-8}$ except some minor discrepancies. Structures and properties do not perfectly correspond between PBDLG and PPDLG. It is due to the difference in the side-chain behavior, namely the stacking properties.

Lotz et $a l .{ }^{5}$ reported that the doublestranded helical structure $\pi \pi_{\mathrm{DL}}^{5.6}$ appeared in PBDLG after heating up to $220^{\circ} \mathrm{C}$. The equatorial reflections were explained by a hexagonal unit cell with dimension $a=18.2 \AA$. Our samples of PBDLG annealed at $220-230^{\circ} \mathrm{C}$ showed the equatorial reflections at spacings $22,15.6,9.0$, and $7.8 \AA$. The first reflection comes from the polar $\beta$ structure, and the others which are explained by a hexagonal unit cell with dimension $a=18.0 \AA$ suggest the presence of the $\pi \pi_{\mathrm{DL}}^{5.6}$ conformation. All annealing treatments caused the transition from $\pi_{\mathrm{DL}}$ to mixtures of $\pi \pi_{\mathrm{DL}}^{5.6}$ and the polar $\beta$ structure. The IR spectra of these mixtures were very similar to that of the original (B) component (Figure 2).

According to Lotz et al., ${ }^{5}$ the dissolution and recasting of $\pi \pi_{\mathrm{DL}}^{5.6}$ from methylene chloride, chloroform (or dioxane), and collidine, gave three other kinds of double-stranded helices, namely, $\pi \pi_{\mathrm{DL}}^{7.2}, \pi \pi_{\mathrm{DL}}^{9.0}$, and $\pi \pi_{\mathrm{DL}}^{10.8}$, respectively. The equatorial reflections were explained by the (pseudo-)hexagonal unit cells with dimensions $a=22.6 \AA \quad\left(\pi \pi_{\mathrm{DL}}^{7.2}\right), 24.7 \AA$ $\left(\pi \pi_{\mathrm{DL}}^{9.0}\right)$, and $26 \AA\left(\pi \pi_{\mathrm{DL}}^{10.8}\right)$. These doublestranded helices have quite large helical cores, the diameters of which are sufficient to hold the respective solvent molecules.

Our PPDLG samples annealed at $200^{\circ} \mathrm{C}$ exhibited several equatorial reflections which were explained by a hexagonal unit cell with dimension $a=25.5 \AA$. The cross section of this unit cell is twice as large as that of the $\pi_{\mathrm{DL}}$ structure of PPDLG. As judged only from the size, it may correspond to the $\pi \pi_{\mathrm{DL}}^{9.0}$ structure. However, this PPDLG film was obtained by annealing, not by using solvents. In the solid state, the transition to a structure having a large vacant core is not feasible. Accordingly, there is a possibility that two single-stranded helices are contained in the unit cell. Such a unit cell has been reported for some polypeptides. $^{18,35,36}$ For the $\alpha$-helical poly(carbobenzoxy L-ornithine), for instance, two crystal modifications are known, and they are characterized by the two-chain hexagonal and the single-chain tetragonal unit cells, respectively. ${ }^{36}$ The molecular arrangement in the two-chain hexagonal unit cell is not clear. In PPDLG, the IR data are useless, since the new form showed the same spectrum as the polar $\beta$ 
structure. Actually, the four kinds of doublestranded helices and the polar $\beta$ structure of PBDLG were shown to exhibit the identical IR spectra. ${ }^{5}$ However, this seems strange, since the structures are quite different. The authors consider that detailed studies are required for these structures.

Acknowledgement. The authors gratefully acknowledge the continueing guidance and encouragement of Dr. A. Abe, Tokyo Institute of Technology.

\section{REFERENCES}

1. B. Lotz, F. Heitz, and G. Spach, C. R. H. Acad. Sci., C276, 1715 (1973).

2. A. Caille, F. Heitz, and G. Spach, J. Chem. Soc., Perkin Trans. 1, 1621 (1974).

3. F. Heitz, B. Lotz, and G. Spach, J. Mol. Biol., 92, 1 (1975).

4. F. Heitz, B. Lotz, and G. Spach, C. R. H. Acad. Sci., C280, 1509 (1975).

5. B. Lotz, F. Colonna-Cesari, F. Heitz, and G. Spach, J. Mol. Biol., 106, 915 (1976).

6. F. Heitz and G. Spach, Macromolecules, 8, 740 (1975); ibid., 10, 520 (1977).

7. F. Heitz, P. D. Cary, and C. Crane-Robinson, Macromolecules, 10, 526 (1977).

8. F. Heitz, G. Detriche, F. Vovelle, and G. Spach, Macromolecules, 14, 47 (1981).

9. M. Tsuboi, Y. Mitsui, A. Wada, T. Miyazawa, and N. Nagashima, Biopolymers, 1, 297 (1963).

10. F. Heitz and G. Spach, Macromolecules, 4, 429 (1971).

11. G. N. Ramachandran and R. Chandrasekaran, Ind. J. Biochem. Biophys., 9, 1 (1972).

12. D. W. Urry, Proc. Natl. Acad. Sci. U.S.A., 69, 1610 (1972).

13. F. T. Hesselink and H. A. Scheraga, Macromolecules, 5, 455 (1972).

14. W. L. Bragg, J. C. Kendrew, and M. F. Perutz, Proc. R. Soc. London, Ser. A, 203, 321 (1950).
15. IUPAC-IUPAB Commission on Biochemical Nomenclature, J. Mol. Biol., 52, 1 (1970).

16. B. W. Low and R. B. Baybutt, J. Am. Chem. Soc., 74, 5806 (1952).

17. B. W. Low and H. J. Grenville-Wells, Proc. Natl. Acad. Sci. U.S.A., 39, 785 (1953).

18. S. Sasaki, Y. Yasumoto, and I. Uematsu, Macromolecules, 14, 1797 (1981).

19. Y. Trudelle, J. Chem. Soc., Perkin Trans. 1, 1001 (1973).

20. P. De Santis, S. Morosetti, and R. Rizzo, Macromolecules, 7, 52 (1974).

21. M. Nagao, T. Suzuki, S. Sasaki, and I. Uematsu, Polym. Bull., 11, 565 (1984).

22. P. Doty, J. H. Bradbury, and A. M. Holtzer, J. Am. Chem. Soc., 78, 947 (1956).

23. S. Sasaki and I. Uematsu, J. Polym. Sci., Polym. Phys. Ed., in press.

24. A. J. McKinnon and A. V. Tobolsky, J. Phys. Chem., 72, 1157 (1968).

25. T. Fukuzawa, I. Uematsu, and Y. Uematsu, Polym. J., 6, 431 (1974).

26. A. Elliott, R. D. B. Fraser, and T. P. MacRae, J. Mol. Biol., 11, 821 (1965).

27. Y. Mitsui, Y. Iitaka, and M. Tsuboi, J. Mol. Biol., 24, 15 (1967).

28. M. Yoshikawa, Y. Tsujita, I. Uematsu, and Y. Uematsu, Rep. Progr. Polym. Phys. Jpn., 15, 641 (1972); Polym. J., 7, 96 (1975).

29. S. Tsuchiya, J. Watanabe, Y. Uematsu, and I. Uematsu, Rep. Prog. Polym. Phys. Jpn., 15, 637 (1972).

30. T. Fukuzawa, I. Uematsu, and Y. Uematsu, Polym. J., 6, 537 (1974).

31. T. Takahashi, A. Tsutsumi, K. Hikichi, and M. Kaneko, Macromolecules, 7, 806 (1974).

32. N. Matsushima, K. Hikichi, A. Tsutsumi, and M. Kaneko, Polym. J., 7, 382 (1975).

33. J. Watanabe, K. Imai, K. Kosaka, A. Abe, and I. Uematsu, Polym. J., 13, 603 (1981).

34. M. Nagao, S. Sasaki, T. Hayashi, and I. Uematsu, Polym. Bull., 9, 11 (1983).

35. S. Kasuya, S. Sasaki, J. Watanabe, Y. Fukuda, and I. Uematsu, Polym. Bull., 7, 241 (1982).

36. S. Sasaki, H. Ban, and I. Uematsu, J. Polym. Sci., Polym. Phys. Ed., 21, 413 (1983). 